\title{
Singularidades de alguns graduandos de Ciências Biológicas e as Políticas Afirmativas na Universidade Federal de Sergipe
}

Singularities of some undergraduate students of Biological Sciences and Affirmative Policies at the Federal University of Sergipe

\author{
A. M. Santana ${ }^{1 *}$; M. C. R. Paranhos ${ }^{1}$; A. A. Pagan ${ }^{2}$ \\ ${ }^{1}$ Programa de Pós-Graduação em Ensino de Ciências e Matemática, Universidade Federal de Sergipe, CEP: 49100- \\ 000, São Cristóvão-SE, Brasil \\ ${ }^{2}$ Departamento de Biologia, Universidade Federal de Sergipe, CEP: 49100-000, São Cristóvão-SE, Brasil
}

*alynedsr@gmail.com

(Recebido em 09 de novembro de 2016; aceito em 24 de janeiro de 2017)

\begin{abstract}
Cada pessoa é única, possui características somente suas dentro de seu modo de pensar, ser e agir. Cada aluno tem seu modo particular de aprender, refletido em sua cultura e experiência de vida. Essas características particulares de ser são entendidas aqui como singularidades. Neste trabalho buscamos descrever algumas das singularidades dos alunos do curso de Ciências Biológicas Licenciatura da Universidade Federal de Sergipe. Entrevistamos 5 graduandos, cujas falas foram transcritas e analisadas a partir da apresentação de trechos que representem a diversidade de singularidades apontadas nas falas dos discentes entrevistados. Analisamos 4 grupos de singularidades, 1) étnico/racial; 2) socioeconômicas, 3) Pessoa com Deficiência e 4) múltiplas jornadas da mulher.
\end{abstract}

Palavras-chave: Políticas afirmativas, Inclusão, Formação de professores de Biologia.

Each person is unique, has only their characteristics within their way of thinking, being and acting. Each student has their own particular way of learning, reflected in their culture and life experience. These particular characteristics of being are understood here as singularities. In this work we seek to describe some of the singularities of the students of the Biological Sciences degree course of the Federal University of Sergipe. We interviewed 5 undergraduates, whose lines were transcribed and analyzed from the presentation of excerpts that represent the diversity of singularities pointed out in the speeches of the students interviewed. We analyzed 4 groups of singularities, 1) ethnic / racial; 2) socioeconomic, 3) people with disabilities and 4) multiple days of women.

Keywords: Affirmative politics, Inclusion, Training of Biology teachers.

\section{INTRODUÇÃO}

No Brasil, e consequentemente, na Universidade Federal de Sergipe (UFS), vivemos um momento de transição dentro do que entendemos como formação profissional. Um momento que envolve amplo processo de inclusão de discentes, que em outros tempos dificilmente entrariam na universidade. Não se tratam de alunos incompetentes, mas que apresentam uma formação intelectual e cultural bastante diferente dos cânones compatíveis com o discurso acadêmico.

O graduando que geralmente ingressa na UFS, apresenta faixa etária de 17 a 29 anos, estes jovens se defrontam com um mundo novo, das atividades de seu curso de graduação. Para alguns, trata-se de um ambiente, totalmente diferente do que ele estava acostumado, especialmente para aqueles que vêm de contextos familiares nos quais não houve introdução da cultura acadêmica.

Esse aluno precisa amadurecer abruptamente a sua postura frente aos estudos, o que demanda habilidades como autonomia, comunicação, resiliência, além de foco, planejamento e concentração nos estudos.

A transição para o ensino superior implica e é concomitante com uma série de mudanças na vida do estudante, cujo impacto depende das características desenvolvimentais do próprio jovem e das exigências e apoios dos novos contextos [1]. 
Ao entrar na universidade o jovem passa por várias mudanças, novos espaços, colegas, modo de se comportar e de estudar [2]. Estas alterações podem causar maiores ou menores níveis de stress que, em certos casos, podem conduzir ao desajustamento, fracasso e abandono acadêmicos. Nesta fase, o aluno passa por múltiplos desafios derivados das tarefas psicológicas normativas essenciais a passagem da adolescência para a vida adulta [3].

Além disso, alguns discentes ainda têm de lidar com mais alguns percalços para obter êxito acadêmico. Nesse contexto insere-se as singularidades, entendemos que, cada pessoa é única e possui características somente suas dentro de seu modo de pensar, ser e agir. Cada aluno tem seu modo particular de aprender, refletido em sua cultura e experiência de vida. Essas características particulares de ser denominamos neste trabalho como singularidades. Estudar e descrever singularidades é importante para auxiliar no processo de inclusão discente de maneira mais eficiente. Observando possíveis barreiras ao desenvolvimento acadêmico discente para que se crie medidas ou políticas afirmativas que possam minimizar essas barreiras.

No início de sua trajetória escolar, o aluno transporta para a escola além da influência cultural de sua comunidade, algo muito profundo, a sua singularidade [4]. Com aspectos próprios, o aluno se lançará no processo da aprendizagem escolar, completando essa trajetória e prosseguindo a sua construção enquanto pessoa nas novas e importantes experiências no espaço social.

Essa diversidade de singularidades remete à necessidade da criação e implantação de políticas afirmativas em vários setores públicos. Trata-se da busca pela superação da padronização do ensino.

No caso das universidades, implantadas a partir dos anos 2000 essas políticas visam, principalmente, a reserva de vagas em universidades públicas, tanto para alunos negros e pardos, quanto para os de classe econômica desprivilegiada. Além de garantir também vagas e condições para que deficientes possam cursar o ensino superior. Porém algumas singularidades não são contempladas por essas políticas.

Em 2004, foi implantada a expansão orgânica das universidades brasileiras com o intuito de universalizar o Ensino Superior. Em agosto de 2012 foi sancionada a Lei $n^{\circ}$ 12.711/2012, garantindo a reserva de $50 \%$ das matrículas por curso e turno nas 59 universidades federais e 38 institutos federais de educação, ciência e tecnologia a alunos oriundos integralmente do ensino médio público, em cursos regulares ou da educação de jovens e adultos. Dessas vagas, uma porcentagem de acordo com a quantidade de negros, pardos e indígenas na localidade da universidade pretendida, são assegurados pela mesma lei [5].

Dados do censo 2014 afirmam que as matrículas de portadores de deficiência aumentaram quase $50 \%$ nos últimos quatro anos, sendo a maioria em cursos de graduação presenciais. Em 2013 eram quase 30 mil alunos, enquanto em 2010 eram pouco mais de 19 mil [6]. Apesar dos dados darem um quantitativo de avanço, não foi divulgado o número de concludentes. É necessária uma legislação que garanta acessibilidade no ambiente acadêmico e que esta seja respeitada, o MEC deve acompanhar a autorização e funcionamento das instituições. A universidade tem um papel social fundamental para a inclusão, buscando um processo educacional mais justo e democrático [7].

As políticas afirmativas são importantes para o avanço da sociedade em geral, foi a partir delas que determinados grupos da sociedade puderam ter voz e garantir direitos iguais aos grupos mais favorecidos. Nas universidades, as reservas de vagas para alunos negros, deficientes e de classe social desprivilegiada deram oportunidades a esses alunos de cursar o nível superior e mudar estigmas sociais. Mas, assim como no caso dos deficientes, pouco se tem feito para garantir a permanência dos cotistas nas universidades.

Nesse sentido, buscaremos nesse trabalho, descrever algumas das singularidades dos alunos do curso de Ciências Biológicas Licenciatura, no processo de inclusão na Universidade Federal de Sergipe.

\section{METODOLOGIA}

Nessa seção procuramos mostrar o caminho metodológico escolhido para atingir nossos objetivos. Escolhemos como método de pesquisa entrevistas e criamos um roteiro com temas 
sobre singularidades. Nas perguntas pedimos aos entrevistados que descrevessem sua história de vida e falassem sobre como eles são, sobre sua infância, adolescência, entre outras perguntas.

Realizamos cinco entrevistas semiestruturadas com alunos de diferentes períodos do curso e idades, bem como atendendo a diversidade de gêneros. Dos 5 entrevistados 4 nos informaram serem cotistas. Todas as entrevistas foram gravadas, com a devida autorização dos entrevistados através do Termo de Consentimento Livre e Esclarecido, e em seguida transcritas. Apresentamos a descrição e a análise das categorias construídas no tópico seguinte.

$\mathrm{Na}$ técnica de entrevista semiestruturada, semelhantemente á estruturada, o pesquisador utiliza um conjunto de questões, mas diverge da outra por permitir que o entrevistado tenha liberdade em discorrer sobre o tema proposto [8].

Para a análise buscamos recortar trechos de falas que se remetessem às identidades discentes que nos dessem pistas sobre suas singularidades a partir de algumas categorias à priori construídas a partir da análise das classes observadas nas Políticas afirmativas: 1) étnico/racial; 2) socioeconômicas e 3) Pessoa com Deficiência. Também, diante de algumas especificidades percebidas nos discursos dos alunos ligados ao gênero: 4) múltiplas jornadas da mulher.

\section{RESULTADOS E DISCUSSÃO}

Os resultados das entrevistas foram organizados conforme as categorias descritas na metodologia. Em cada uma delas, buscamos mostrar falas que explicassem qual o tipo de singularidade identificada, que fato na biografia do discente levou àquela singularidade, bem como resultados relacionados a ela, positivos e negativos. Foram entrevistados 5 alunos, sendo 3 do sexo feminino e 2 do sexo masculino. A idade deles está entre 21 e 34 anos, dois dos alunos estão no segundo período, outros dois no sexto e um está no oitavo.

\subsection{Singularidades relacionadas à aspectos étnicos raciais}

Aspectos étnicos raciais são características ligadas à raça e etnia, como negros, pardos, indígenas, quilombolas. Em agosto de 2012 foi sancionada a Lei $\mathrm{n}^{\circ}$ 12.711/2012, garantindo a reserva de vagas nas universidades de uma porcentagem de acordo com a quantidade de negros, pardos e indígenas na localidade da universidade pretendida [5].

A luta do homem contra a discriminação racial teve suas origens nas ideias defendidas pela Independência Americana, em 1776, e na Revolução Francesa, em 1789, no surgimento dos ideais democráticos e, principalmente, na luta dos homens pelos seus direitos naturais [9].

Não foi observado em nenhuma fala a auto identificação, por parte dos discentes, como sendo negros ou indígenas ou quilombola. E nenhuma fala apresentou relação desses grupos com os entrevistados.

\subsection{Singularidades relacionadas à aspectos socioeconômicos}

Aspectos socioeconômicos dizem respeito à classe econômica dos entrevistados. Na mesma lei citada anteriormente temos a reserva de vagas de $50 \%$ das matrículas por curso e turno para alunos oriundos de escolas públicas, com renda de até 1,5 salário mínimo [5].

Quatro dos entrevistados entraram na universidade através das cotas socioeconômicas, são de escolas públicas. E nas falas observamos que as condições financeiras são desprivilegiadas, além de falas que indicam que são interioranos.

Fiz o ensino médio todo no colégio Atheneu. Sempre fui do ensino público, meu pai não tinha condição de bancar particular pra gente (F34).

Entrei pelo sistema de cotas, o grupo g se não me engano que é pra brancos e 1 salário e meio (F26).

[...], mas eu era bem tabaroa mesmo né? Aquela coisa do interior, não tinha esses avanços de hoje dessas meninas mais avançadas, sou das antigas mesmo mais tranquila (F35). 


\subsection{Singularidades relacionadas à pessoa com deficiência}

Não houve nenhuma fala em que os entrevistados tenham se auto identificado como pessoa portadora de deficiência. Entretanto houve uma fala que trouxe um caso de aluna deficiente.

[...] eu conheço um caso aqui na universidade, a pessoa é deficiente, ingressou pelo sistema de cotas e sofre preconceito da turma. Ela se sente desestimulada e humilhada pelos próprios professores e colegas de curso. Já pensou em abandonar, reprova em disciplinas que precisam fazer trabalho em grupo porque os colegas não querem ela (no grupo) (F21).

A universidade aparentemente não está preparada para acolher esses alunos com deficiências.

De fato, alunos com deficiência já abandonaram cursos na UFS migrando para as faculdades particulares por causa da falta de estrutura da nossa Universidade; por causa da indiferença e até da hostilidade de alguns professores; tudo isso somado à burocracia da instituição, carecendo esta de celeridade na resolução de seus problemas para o efetivo acolhimento que contribuiria para a permanência e a terminalidade da inclusão nos cursos da UFS [10].

\subsection{Singularidades relacionadas às múltiplas jornadas da mulher}

Algumas falas remetem às múltiplas jornadas das mulheres, ser casada, ser mãe, ou até assumir esse papel de matriarca são singularidades observadas nos discursos.

Eu tenho 34 anos, sou solteira tenho uma filha (F34)

Sou casada tenho dois filhos (F26).

Eu fui criada por meu pai desde os 6 anos, meus pais se separaram e eu fiquei com meu pai [...] quando meus pais se separaram meu pai voltou muito essa frustração dele pra mim em relação à separação... e.... a gente tinha muitas discordâncias (F34).

Pesquisadoras em seu estudo com mulheres de Santa Catarina, que assumem o papel de chefes de família, relatou que dentre as dificuldades que as entrevistadas afirmaram enfrentar, as múltiplas jornadas de trabalho, as estratégias para conciliar as responsabilidades domésticas com vida profissional foram citadas [11].

O fato de ser casada, de ter filhos, ou assumir o lugar de mãe na família implica em algumas consequências como a responsabilidade, amadurecimento:

Casei também aí também tive que ter outro tipo de postura né? Atribuo a isso: casamento filhos aí fui amadurecendo (F26).

Eu engravidei cedo, aí por isso... aí a responsabilidade influenciou. Então, esse fator fez com que eu mudasse totalmente meu jeito de ser, meu modo de pensar, e de agir também (F26).

Com o abandono de minha mãe e tudo teve essa carga né, esse peso de que eu era a única mulher, era eu meu pai e meu irmão, ele era mais novo que eu e eu tinha essa carga de responsabilidade acima de uma pessoa da minha idade (F34).

Essas consequências podem trazer aspectos positivos e negativos. Ao adquirir responsabilidade ela se torna uma pessoa mais madura confiante e confiável, porém essas responsabilidades podem dividir a atenção da discente e prejudicar o desenvolvimento acadêmico da mesma.

Mas depois também me tornou a pessoa que sou hoje, eu sou uma pessoa que eu corro atrás que eu vou atrás eu não tenho medo de encarar as coisas então tudo tem um motivo ne tudo tem uma serventia (F34).

Já, tipo, situações... perder matéria, tipo eu não foco só aqui na universidade, entende, meu lado pessoal acaba interferindo. [...] Tipo saber a hora que tem que parar um pouco pra dar mais atenção ao lado pessoal e a hora que eu tenho que focar mais no lado da universidade. Por isso que no próximo período eu vou focar mais (F26). 


\section{CONCLUSÃO}

Embora as políticas afirmativas tenham trazido importantes contribuições e possibilitado a entrada de estudantes de classes populares, grupos étnicos e portadores de deficiências no meio acadêmico, esta entrada ainda carece de políticas de permanência dos discentes na universidade. Na UFS, o foco das atividades inclusivas tem sido os estudantes com deficiência, no entanto, pouco se fala sobre as demais especificidades.

Esse tipo de medida observada é classificado como Inclusão Assimilacionista, que consiste em colocar todos os sujeitos sob uma mesma realidade, inseridos numa cultura homogênea, que deve ser criticada e revista [12].

Diante disso, defende-se a inclusão aberta e interativa, focado na interculturalidade a fim de construir uma sociedade mais democrática e inclusiva, visando políticas de igualdade e identidade visando relacionar os indivíduos de diversas culturas sem perder sua identidade cultural [12].

Assim, consideramos a necessidade de que as políticas afirmativas dentro da instituição sejam ampliadas dando conta da criação de espaços de autoconhecimento e desenvolvimento de habilidades que visem o fortalecimento das singularidades, de maneira que as mesmas sejam vistas como potencial singular em cada indivíduo. No caso dos resultados desta pesquisa, apontamos para a necessidade de discussões no campo feminista, do desenvolvimento socioeconômico, além disso, é de espantar que nenhum dos alunos tenha discutido singularidades relacionadas à questão étnico racial, o que pode indicar mesmo uma invisibilidade sobre a questão racial.

\section{AGRADECIMENTOS}

CNPq, Programa de Pós-Graduação em Ensino de Ciências e Matemática (PPGECIMA).

\section{REFERÊNCIAS BIBLIOGRÁFICAS}

1. Santos L, Almeida LS. Vivências académicas e rendimento escolar: Estudo com alunos universitários do 1. ${ }^{\circ}$ ano. In: Análise Psicológica. 2001;(2):205-217.

2. Almeida LS, Guisande MA, Soares AP, Saavedra L. Acesso e Sucesso no Ensino Superior em Portugal: Questões de Género, Origem Sociocultural e Percurso Académico dos Alunos. In: Psicologia: Reflexão e Crítica. 2006;19(3):507-514.

3. Cunha SM, Carrilho DM. O Processo de Adaptação ao Ensino Superior e o Rendimento Acadêmico: Adaptação e Rendimento Acadêmico. In: Psicologia Escolar e Educacional. 2005;9(2):215-224.

4. Tacca MCV R, González-Rey FL. Produção de Sentido Subjetivo: As Singularidades dos Alunos no Processo de Aprender. In: Psicologia, Ciência e profissão. 2008;28(1):138-161.

5. Brasil, Ministério da Educação. Disponível em <http://portal.mec.gov.br/cotas/legislacao.html> Acesso em 27 Abr. 2015. 3 p.

6. Brasil, Instituto Nacional de Estudos e Pesquisas Educacionais Anísio Teixeira (INEP). Disponível em $<$ http://portal.inep.gov.br/visualizar/-/asset_publisher/6AhJ/content/matriculas-no-ensino-superiorcrescem-3-8> Acesso em 05 Mai. 2015.

7. Rocha TB, Miranda TG. Acesso e permanência do aluno com deficiência na instituição de Ensino Superior. In: Revista Educação Especial. Santa Maria. 2009;22(34):197-212.

8. Pádua EMM. Metodologia da pesquisa: Abordagem Teórico-Prática. 13. Ed. São Paulo: Papirus; 2007. $94 \mathrm{p}$.

9. Bittar M, Almeida CEM. Mitos e controvérsias sobre política de cotas para negros na educação superior. In: Educar, Curitiba. 2006;28(1):141-159.

10. Souza VRM. A inclusão do aluno com deficiência na Universidade Federal de Sergipe. In: Marcon F, Subrinho JMP (Orgs). Ações afirmativas e políticas inclusivas no ensino público superior: a experiência da Universidade Federal de Sergipe. São Cristovão: Editora UFS, 2010. 127-144.

11. Perucchi J, Beirão AM. Novos arranjos familiares: paternidade, parentalidade e relações de gênero sob o olhar de mulheres chefes de família. In: Psic. Clin., Rio de Janeiro. 2007;19(2):57-69.

12. Candau VM. Multiculturalismo e educação: desafios para aprática pedagógica. In: Moreira AF (ORGs). Multiculturalismo: Diferenças culturais e práticas pedagógicas. $2^{\mathrm{a}}$ Edição. Petrópolis- RJ: Editora Vozes, 2009. 245 p. 